$06 ; 15$

\title{
Многопараметровый контроль многослойных структур импульсным вихретоковым методом
}

\author{
() Д.С. Малушин \\ МИРЭА - Российский технологический университет, Москва, Россия \\ E-mail: box_of_mail@mail.ru
}

Поступило в Редакцию 18 октября 2018г.

В окончательной редакции 14 января 2019 г.

Принято к публикации 25 апреля 2019г.

\begin{abstract}
Предложена многопараметровая методика импульсного вихретокового контроля, позволяющая проводить раздельное количественное определение более семи параметров многослойных структур, содержащих магнитные составляющие. Продемонстрировано применение методики для контроля качества слабопроводящих магнитных покрытий и слоистых композиционных материалов, применяемых в аэрокосмической отрасли.
\end{abstract}

Ключевые слова: импульсный вихретоковый метод, многопараметровый неразрушающий контроль, многослойные структуры, композитные материалы, магнитные материалы.

DOI: 10.21883/PJTF.2019.15.48080.17570

Современное высокотехнологичное производство требует создания новых материалов, позволяющих снизить вес изделий и одновременно обеспечить их высокую механическую и коррозионную стойкость. К таким материалам можно отнести композиционные материалы, изготовленные из электропроводящих компонентов магнитных и немагнитных типов, которые нашли широкое применение в области легкого и среднего машиностроения при изготовлении подшипников скольжения, изделий из листового проката с плакирующим покрытием и экранирующих покрытий различных типов, а в области авиационной техники - при изготовлении крыльев, хвостового оперения и фюзеляжа современных летательных аппаратов.

Распространенными композиционными материалами в авиации являются металлополимерные слоистые алюмостеклопластики класса СИАЛ $\left(\mathrm{GLARE}^{\mathrm{TM}}\right)$, алюмоорганопластики класса АЛОР и алюмоуглепластики класса АЛКАР, состоящие из тонких (0.3-0.4 mm) листов алюминиевого сплава и клеевых препрегов различной структуры (кордной стеклоткани, ровинга из высокомодульного стекловолокна, арамидных органопластиков или углепластика $[1,2])$.

В изделиях из биметаллов или плоских слоистых композитов в толще материала возможно возникновение областей несплошности (таких как пористость), а также расслоений [3], коррозионных или усталостных растрескиваний [4], межслойной коррозии (в частности, питтинговой) или областей истончения внешних слоев материала.

В работах [5,6] был проведен анализ применимости отдельных методов неразрушающего контроля для определения количественных характеристик подобных нарушений структуры, который показал, что вихретоковые методы (наряду с акустическими, тепловыми и радиационными) по-прежнему остаются наиболее востребованными.

Однако существующие методики вихретокового контроля [7-9], как правило, позволяют производить количественное определение не более трех типов повреждений структуры многослойного материала: расслоения, трещины (или пористость) и коррозия, что в ряде случаев может оказаться недостаточным для комплексного анализа состояния конкретного объекта. Более того, для многослойных структур, содержащих магнитные слои, предлагаемые методики в принципе не позволяют проводить раздельное определение параметров.

Авторы последних исследований в области вихретокового контроля [9] приходят к выводу о необходимости повышения информативности диагностики многослойных материалов за счет увеличения числа контролируемых параметров (от четырех) и увеличения чувствительности вихретокового оборудования, что в совокупности позволит выявлять признаки нарушения структуры уже на ранних стадиях их возникновения.

Использование многопараметровой высокочувствительной методики могло бы привести к сокращению прямых и косвенных затрат на проведение неразрушающего контроля многослойных материалов за счет повышения скорости процесса контроля и увеличения временни́х интервалов между плановыми проверками.

Предлагаемая оригинальная методика позволяет производить раздельное количественное определение более семи диагностических параметров: толщина отдельных электропроводящих слоев, величина относительной магнитной проницаемости их материала, локальные изменения значения удельной электрической проводимости (связанные с наличием трещин, пористости или механическими напряжениями, предшествующими образованию усталостных трещин [4]), величина расслоения и глубина его залегания в толще материала, толщина и 

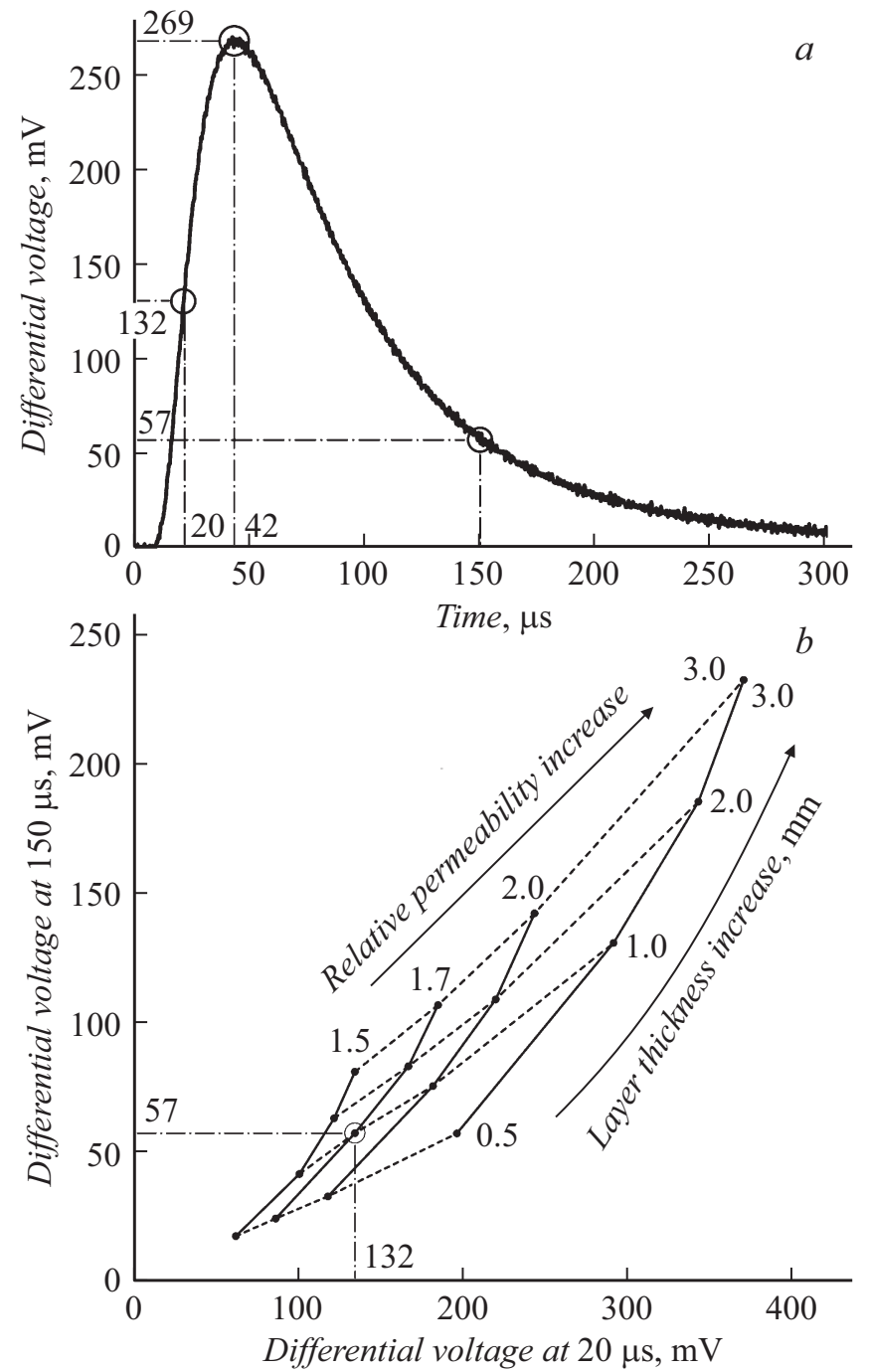

Рис. 1. Методика определения параметров слабопроводящего магнитного покрытия на неферромагнитном основании. $a-$ информативные параметры дифференциального вихретокового сигнала, $b-$ градуировочная характеристика „плоскость состояния".

площадь межслойных коррозионных поражений (включая питтинговую коррозию) и др.

При разработке методики была использована математическая модель [10] накладного вихретокового преобразователя, расположенного над многослойной структурой, каждый слой которой характеризуется значениями толщины, удельной электрической проводимости и относительной магнитной проницаемости.

После проведения численного моделирования в амплитудно-временно́м распределении кривых вносимого магнитного потока и напряжения были выделены информативные признаки, связанные с изменением контролируемых параметров многослойных структур.

Практическая реализация методики осуществляется путем анализа амплитудно-временно́го распределения разности сигналов, полученных с помощью дифферен- циального накладного вихретокового преобразователя от контролируемой области и области материала без повреждений. Измеренные значения информативных признаков разностных сигналов сопоставляются со специальными градуировочными характеристиками („плоскостями состояния“").

Информативными параметрами дифференциального вихретокового сигнала (рис. 1,a) являются его максимальное значение, время, соответствующее этому значению, а также мгновенные значения вносимого напряжения, измеренные в два момента времени, отвечающие определенным критериям [11].

Например, значения толщины $\delta$ слабопроводящего (до $0.15 \mathrm{MS} / \mathrm{m}$ ) покрытия и относительной магнитной проницаемости $\mu$ его материала вычисляются путем определения характеристической точки на „плоскости состояния“ (рис. $1, b)$, координаты точки при этом соот-

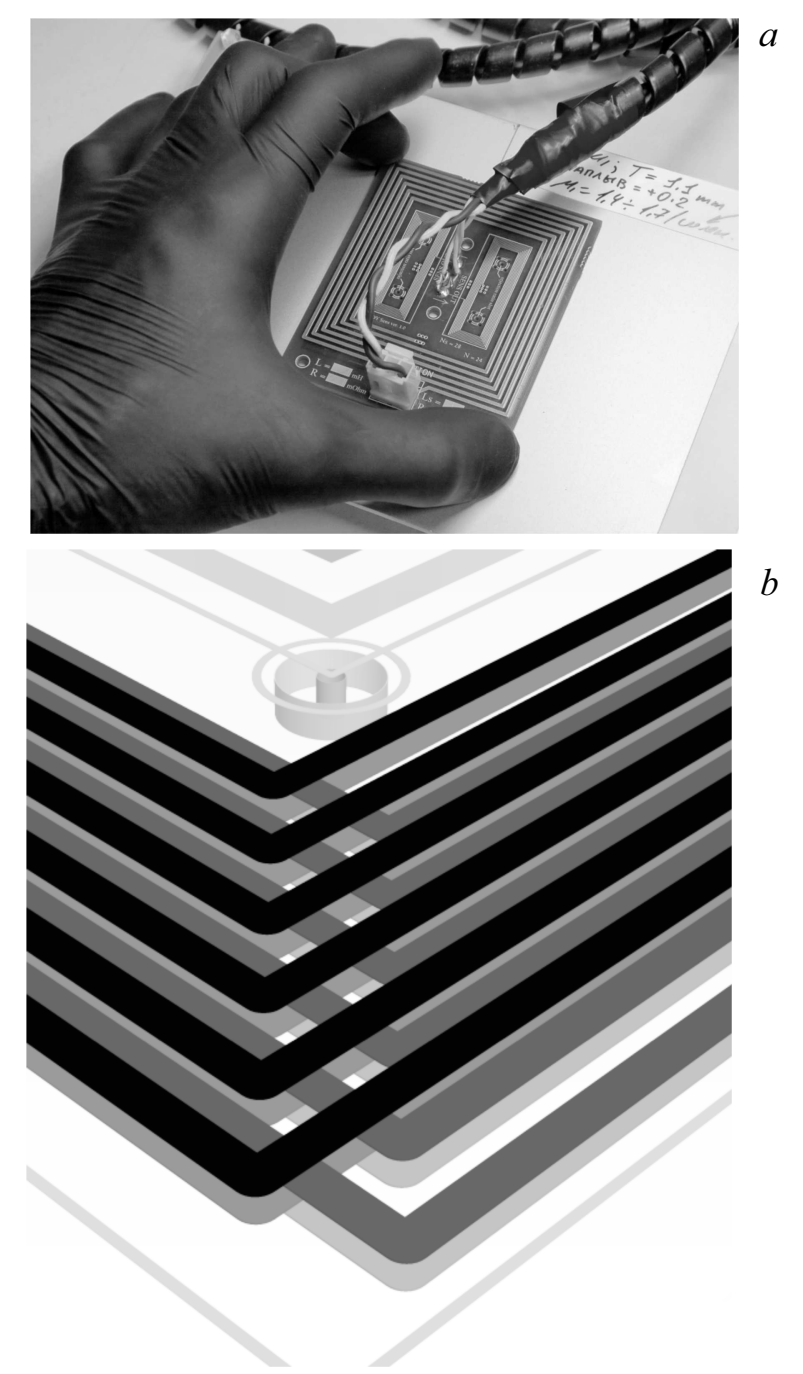

Рис. 2. Дифференциальный накладной вихретоковый преобразователь. $a-$ ручное позиционирование преобразователя над поверхностью многослойной структуры класса СИАЛ, $b-$ схематическое расположение токоведущих частей измерительной катушки в четырех плоскостях. 

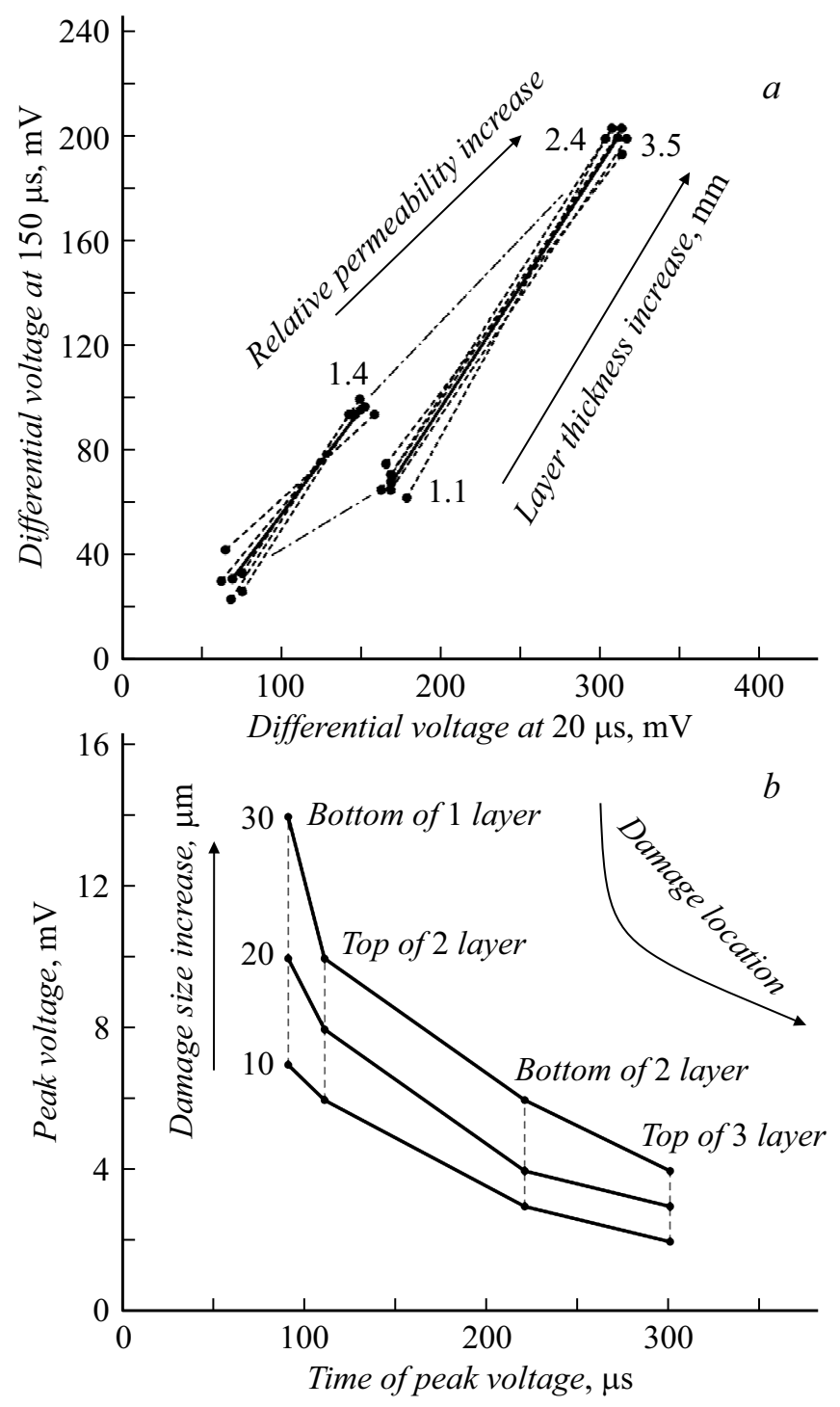

Рис. 3. Градуировочные характеристики, полученные экспериментально. $a$ - для определения параметров защитных магнитных покрытий, $b$ - для определения размера и глубины залегания областей коррозии в трехслойном материале.

ветствуют мгновенным значениям дифференциального сигнала в 20 и $150 \mu \mathrm{s}$ (рис. $1, a)$.

Данная методика может также применяться при решении актуальной задачи определения объема и толщины слабопроводящих магнитных отложений, образующихся на поверхностях трубок теплообменного оборудования АЭС $[11,12]$.

При контроле качества авиационных композитных материалов предлагаемая методика может использоваться для выявления межслойной коррозии, механических напряжений и областей усталостного разрушения в отдельных электропроводящих слоях, а также для обнаружения областей расслоения и глубины их залегания. В этом случае „Плоскость состояния“ строится в осях, по одной из которых откладывается значение максимума дифференциального сигнала, а по другой - смещение по оси времени пика его амплитудно-временно́го распределения [10].

Эффективность разработанной методики контроля многослойных структур была проверена в ходе проведения серии лабораторных экспериментов.

Объектом контроля в первом случае был алюминиевый лист (АМг2) толщиной $2 \mathrm{~mm}$ с магнитными слабопроводящими покрытиями толщиной от 1.1 до $3.5 \mathrm{~mm}$ из отвержденной смеси порошков алюминия (АМг2) и окислов железа $\left(\mathrm{Fe}_{2} \mathrm{O}_{3}, \mathrm{Fe}_{3} \mathrm{O}_{4}\right)$, а также фенолформальдегидной смолы и этилацетата.

Во втором случае объект контроля представлял собой клееную трехслойную структуру из алюминиевых пластин (Д16АТ) толщиной $1.5 \mathrm{~mm}$, на поверхностях которых электрохимическим способом были выращены локальные коррозионные поражения глубиной от 10 до $30 \mu \mathrm{m}$ и области питтинговой коррозии с диаметром каверн до $1.5 \mathrm{~mm}$ и глубиной около $40 \mu \mathrm{m}$ (при плотности поражений около 5 на $10 \mathrm{~mm}^{2}$ ).

В третьем случае в качестве объекта контроля использовалась пятислойная клееная регулярная структура из трех алюминиевых листов (Д16АТ, $0.5 \mathrm{~mm}$ ) с анодно-окисным покрытием и двух листов стеклопластика (FR-4, $0.5 \mathrm{~mm})$. Между отдельными слоями структуры были размещены вставки прямоугольной формы $(20 \times 20 \mathrm{~mm}$, толщина 60 и $125 \mu \mathrm{m})$ из политетрафторэтилена, имитирующие расслоения.

Реализация методики проводилась с помощью специально разработанного лабораторного оборудования. Для создания в возбуждающей катушке прямоугольных импульсов тока с крутым фронтом был использован генератор импульсов напряжения специальной формы. С целью повышения чувствительности измерительного тракта были разработаны прецизионная измерительная система с динамическим диапазоном более $84 \mathrm{~dB}$ и специальный дифференциальный накладной вихретоковый преобразователь (рис. 2,a), конструкция измерительных катушек которого (рис. 2,b) обеспечивает высокий уровень их балансировки (более $72 \mathrm{~dB}$ ).

В ходе проведения серии экспериментов были получены градуировочные характеристики (рис. 3), подтверждающие результаты теоретических оценок и численного моделирования: экспериментальная диаграмма на рис. 3, $a$ является фрагментом модельной диаграммы, показанной на рис. $1, b$, а экспериментальная градуировочная сетка на рис. $3, b$ соответствует модельной плоскости состояния, описанной в [10].

Таким образом, впервые предложена многопараметровая методика импульсного вихретокового контроля, позволяющая проводить раздельное количественное определение более семи параметров различных многослойных структур, таких как биметаллические изделия и слоистые композиционные материалы. 


\section{Список литературы}

[1] Sinmazcelik T., Avcu E., Ozgur Bora M., Ooban O. // Mater. Design. 2011. V. 32. P. 3671-3685.

[2] Лукина Н.Ф., Дементьева Л.А., Серехкенков А.А., Котова Е.В., Сенаторова О.Г., Сидельников В.В., Куцевич К.E. // Рос. хим. журн. 2010. T. LIV. № 1. С. 53-56.

[3] Hashagen F., de Borst R. // Comput. Meth. Appl. Mech. Eng. 2000. V. 185. P. 141-159.

[4] Khan S.U., Alderliesten R.C., Benedictus R. // Int. J. Fatigue. 2011. V. 33. P. 1292-1303.

[5] Sinke J. // Appl. Compos. Mater. 2003. V. 10. P. 277-291.

[6] Ibarra-Castanedo C., Avdelidis N.P., Grinzato E.G., Bison P.G., Marinetti S., Cochior Plescanu C., Bendada A., Maldague X.P. // Int. J. Mater. Product Technol. 2011. V. 41. P. 5-16.

[7] Bonavolonta C., Valentino M., Marrocco N., Piero Pepe G. // IEEE Trans. Appl. Supercond. 2009. V. 19. P. 808-811.

[8] Zhang K., He Y., Dong Z. // J. Sensors. 2018. V. 2018. P. 1639387 (1-11). https://doi.org/10.1155/2018/1639387

[9] Sophian A., Tian G., Fan M. // Chin. J. Mech. Eng. 2017. V. 30. P. 500-514.

[10] Малушин Д.С., Пастухов Е.Г., Журавлёв А.И., Чернов Л.А. // Контроль. Диагностика. 2014. № 9 (195). С. $33-$ 39.

[11] Малушин Д.С., Чернов Л.А. // Приборы. 2014. № 6. С. 4448.

[12] Чернов Л.А., Малушин Д.С., Лунин В.П., Пастухов Е.Г. Патент № 143178 РФ // Бюл. № 20 от 20.07.2014. 